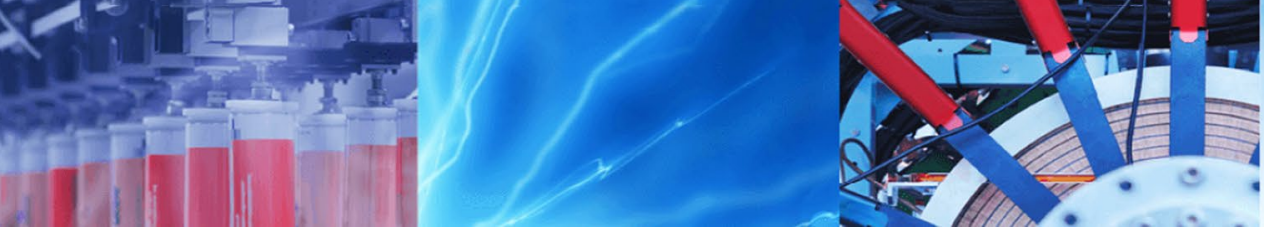

Case Study

\title{
Comparison between collective protective systems in Brazil: safety platforms and safety net type $\mathrm{V}$
}

\author{
Milton César Anjoletto Filho ${ }^{1}$. Sheyla Mara Baptista Serra ${ }^{2}$ (I)
}

Received: 21 May 2020 / Accepted: 4 November 2020 / Published online: 5 December 2020

(c) Springer Nature Switzerland AG 2020

\begin{abstract}
Safety planning is fundamental for accident prevention in the construction industry. The prevention of the risk of accidents in construction must begin during the project development phase through the principles of safe work. Designing minimizing the risk should always be the goal from the first stages of any conception, including designing components or protection systems for construction. The implementation of collective protective systems (CPS) acting as barriers must be professionally designed, detailed, and executed. This article compares two types of collective protective used in Brazil-secondary platforms and the fall arrest system with safety nets, focusing on the building periphery and mitigating the risk of falling from a height. The research method includes the technical visits in two construction sites and the analysis of two CPS designs. The comparison between collective protection systems identified that the system with safety nets better meets standardization criteria and legislation. The analysis of the designs showed a lack of technical information for the execution of the CPS and that it is necessary to make comparisons for decision-making on the existing collective protection systems. The repetition of this approach in countries that use solutions like Brazil can help avoid falls from height.
\end{abstract}

Keywords Accident prevention · Falls from height $\cdot$ Health and safety · Prevention through design · Construction industry · Construction site

\section{Introduction}

The complexity of the construction sector and the different dangers and risks to which workers may be exposed during the execution of the works require high levels of planning and control to mitigate the risk of industrial accidents and prevent occupational diseases [1]. Although the major accidents at the construction site are due to falls from height, there are safety risks due to collisions of motor vehicles, excavation, electrocution, machinery, and falling objects [2]. The main health risks at the site are the use of asbestos, solvents, noise, and manual handling activities [2]. From 2003 to 2013, fatal injuries in the private construction industry in the USA decreased by $27 \%$ [3], from a total of 1131 deaths in 2003 to 828 in 2013. From 2011 to 2013 , falls from a height were mainly related to falls from roofs, stairs, scaffolding, and stays. The falls from height (FFH) are the leading cause of mortality in the construction sector in the USA, and accidents, in general, are caused due to falls in floors or roofs [4]. For these authors, the primary safety measure for the workers should be preventing their fall and not the attempt to protect them after it happens. In this case, the main means of prevention is using barriers such as covers or grids to prevent workers from falling into these openings.

In Brazil, about 3.5 million occupational accidents were identified between 2012 and 2017, covering all economic segments. The construction of buildings registered 96,985

Sheyla Mara Baptista Serra, sheylabs@ufscar.br | ${ }^{1}$ Federal University of São Carlos (UFSCar), São Carlos-SP, Brazil. ${ }^{2}$ Department of Civil Engineering (DECiv), Federal University of São Carlos (UFSCar), São Carlos-SP, Brazil. 
accidents (2.74\% of the total). Among the most affected occupations are the general laborer (2.94\%), the bricklayer (1.24\%), the storekeeper (1.05\%), and the carpenter $(0.59 \%)$. Among the causative agents are the fall of the same level (13.03\%) and the fall from height (6.22\%) [5].

A study in Indian building construction sites reveals that tasks are $13.3 \%$ of low risk, $37.7 \%$ of medium risk, $44.4 \%$ of high risk, and $4.6 \%$ of extreme risk [6]. Through the obtained results noted that crane operation (10.4\%), height work (9.1\%), and drilling (8.8\%) were the three significant tasks with high risk. Besides that, they identified that there is a higher level of disagreement in using personal protective equipment (PPE) by the workers.

Globally, FFH is among the leading causes of severe and fatal injuries for construction workers [7]. For these authors, the most common factors associated with FFH are risky activities, individual characteristics of workers, construction site conditions, organizational culture, agents (scaffolds/ladders), and weather conditions. The results contributed to identifying actions aimed at improving safety projects, promoting behavioral investigations, and adopting methods of preventing $\mathrm{FFH}$, such as training of workers and engineering facilities [7]. Other results found that the causes that contribute to the fall hazards are communication barriers [8]. For those authors, the causes of fall accidents in the construction industry too can be attributed to workers' negligence, failure of workers to obey work procedures, work at high elevation, operating equipment without safety devices, poor site management, failure to use PPE, and low workers attitude about safety.

According to the different types of accidents that may happen in the construction environment, several kinds of barriers or collective protective equipment (CPE) or collective protective system (CPS) for preventing the risk of accident collectively and not attached to the human body can be devised. Collective protection is equipped to protect more than one person and, once correctly installed or constructed, requires no further action to ensure that, if necessary, it will work to prevent accidents or mitigate the consequences of accidents [9].

There is a greater risk of falls by workers near peripheries and openings in floors under construction [10]. According to [11], CPS can be installed in the edges effectively, since it eliminates the risk at the source, avoiding falls and injuries to the worker. This system is also meant as temporary because its installation occurs or remains in place for a limited, foreseen, and determined time. Thus, several standardization agencies present standards or guidelines for the installation of CPS and consequent reduction in work-related accidents.

Researchers also seek to understand the advantages among the available CPS options on the market [12]. [13] followed the slab formwork assembly phase in constructing a building in Spain to assess the risks of workers falling. They compared four different fall protection systems used to prevent such risks. The research results showed that all the safety systems analyzed had several weaknesses that must be studied in detail before using construction sites.

In Brazil, the existence of two different types of CPS focused on the prevention of FFH is observed in multifloor buildings with concrete structures with block seals: the secondary platforms and the fall arrest system with safety nets. The objective of this study is to present a comparison between two CPS through the analysis of the design with safety and compliance with safety standards.

\section{Standards for the installation of CPS}

The standard "Number 735: Health and Safety: The Work At Height Regulations 2005" [9] describes the measures of prevention and control of falls from height. In schedule 3 , "requirements for working platforms" is mentioned that the working platform shall: (a) be of sufficient strength and rigidity for the purposes for which it is intended; (b) be used as to ensure that its components do not become accidentally displaced; (c) when altered or modified, need to ensure that it remains stable; and (d) be dismantled in such a way as to prevent accidental displacement. This standard, too, presented the "additional requirements for scaffolding" that determine the realization of strength and stability calculations for scaffolding and depending on the complexity of the equipment selected, the elaboration of an assembly plan, use, and dismantling. For application on the construction site, an engineering procedure can be developed with specific details of the equipment.

For "directive 2009/104/EC: use of work equipment" [14], the risk of falls from a height represents a large proportion of all accidents at work, especially fatal accidents. The employer must install collective protective equipment to minimize the risk of accidents for workers. Competent professionals must accompany the design, assembly, use, initial inspection (before commissioning), and periodic inspections of CPS to ensure the proper functioning of the equipment.

The Occupational Health and Safety Administration (OHSA) in the SN 1926.502: Fall protection systems criteria and practices [15] presents several standards related to the construction and protection against falls. This standard also mentions the need to install systems to protect against falls from a height. In the item 1926.502 (c), the standard presents the option of installing "safety net systems," which must follow technical guidelines for its design and maintenance. 
In Brazil, "regulatory standard 18 (NR-18): working conditions and environment in the construction industry" in the item "18.13 measures of protection against falling height" mentions that it is mandatory to install collective protection where there is a risk of falling persons or materials [16]. Among the possible technical solutions are the primary and secondary platforms and the fall arrest system with safety nets.

If there is a risk of falling from a height, international standards establish that, firstly, to eliminate the risk of a fall in the source, incorporating integrated protection measures to the very structure of the building. During this analysis, it may be necessary to make design changes or incorporate devices that increase the safety of users [17]. However, CPS is not always properly designed or installed. The development of designs for safety must aim at the services being executed during the construction phase and the correct installation of the equipment. According to [18], the design with safety is a specific design aimed at ensuring the protection of workers through specifications, detailing, and elaboration of collective and individual protection.

Based on the study [19], to choose the appropriate CPS to prevent falls from heights in construction sites, it is necessary to analyze: height of fall risk; easy installation of the safety system; coverage of the potential drop zone with protective equipment; risk of injury during fall; possibility of injury during impact with protective equipment; case of damage by falling debris, materials and equipment; easy rescue and possibility of injury during the recovery. There are several CPS solutions available on the market regulated by Brazilian safety legislation. So, for the effective implementation of the workers' health and safety management at the construction site, it is necessary to propose collective prevention measures in the sites, starting with the preparation of a "design for the implementation of collective protective following the implementing steps of the work," as determined by the NR-18 [16].

\section{Elaboration of the design with safety}

Although it may be possible to reduce the risk represented by hazards during the preparation of the detailed design, the control measures must be specified from the early stages of the project and the contract [20]. The elaboration of design with safety requires a holistic view of all the phases that make up the construction process and execution, with the main emphasis in the pre-construction phases-conception, planning, and design [21]. The design aimed at ensuring the safety of workers must include drawings, diagrams, details, and specifications of materials that facilitate the understanding of construction agents.
The prevention of the risk of accidents in construction through design must be a process in which the engineers and architects explicitly consider the workers' safety [22]. However, the literature addressing technical principles to help designers plan better performing products is not widespread. For these authors, designers should choose the inherently safer systems, understand construction engineering, and increasingly apply spatial considerations to reduce workers' risks.

The product design should be developed in a way that offers safety to the user. In construction, safety principles should be followed at the design stage of the product, service, or process. Several authors have identified terms that meet this consideration: design for safety-DFS [23]; design for construction safety-DFCS [24]; prevention through design-PtD [25]; construction hazards prevention through design-CHPtD [22]; and design for construction worker safety-DCWS [26].

The safe design begins with developing the product, service, or process concept and considers safety at each stage of its life cycle. The purpose of the product or process must be observed, materials to be used, possible methods of construction, maintenance, operation, demolition, or disassembly; legislation, standardization, and codes of practice that need to be followed [27].

In England, construction regulations recommend that a single company is responsible for managing the teams that contribute to health and safety. The entrepreneur is no longer exclusively responsible for ensuring health and safety during construction [28]. Moreover, these authors also indicate the difficulty encountered by entrepreneurs in preparing health and safety plans for the building phases.

In Brazil, the health and safety planning is linked to the "program of working conditions and environment in the construction industry" (in Portuguese: PCMAT-"Programa de Condições e Meio Ambiente de Trabalho na Indústria de Construção") [16]. By law, this must be prepared by a skilled safety professional, although not always having professional training in the construction area. The NR-18 determines the elaboration of protection measures to prevent accidents at work and presents several project and management recommendations that need to be followed, as will be explained below.

\section{Collective protective systems (CPS)}

To choose a CPS for the mitigate of fall from a height, [19] recommends that the following: effectiveness in preventing risk for construction workers and the general public, the impact on completing the work, the cost, and the quality of the system. 


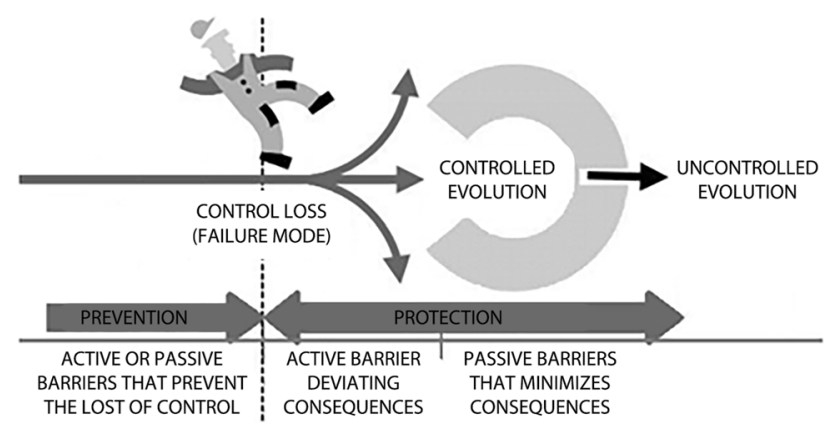

Fig. 1 Concept of barriers for protection and prevention of accidents. Source: [29]

Collective protective is defined, according to the classification proposed by [29], as physical or functional barriers designed to prevent accidents but not incorporated into the workers' body or clothing. The barriers that are integrated into the body or clothing are called personal protective equipment (PPE) and are not part of the main scope of this work. Figure 1 shows the classification of barriers related to an accident.

[29] presents the difference between prevention barriers, which have their functions planned for an accident that has not yet occurred (considering it an occurrence hypothesis), and the protective barriers whose role is to protect those involved in the accident after it has already happened. The collective prevention measures against falls from height from construction most effectively used in Brazil, according to NR-18 [16], are lateral closings with metallic components and safety nets, protection of openings in the floor and wall, slab edge protection with guardrail perimeter, bulkheads for the closing of horizontal and vertical spaces, primary, secondary, and tertiary protection platforms, and guide cable for harness fixing. The equipment can be used together, forming an accident prevention system.

The platforms or trays are used in buildings with 4 floors or more to protect workers from falling and prevent the projection of materials, retaining the falling object on its floor. They may be subdivided into primary platforms (installed right after the concreting of the first slab of the building), and secondary (installed every three floors above the primary platform). The elements of the platforms are the metallic components, fixing hooks, and the wooden floor (Fig. 2). Some designers recommend using anchor bars to fix the metallic structure of the platform better to avoid the oscillation of the assembly by the action of the wind. The entire perimeter of the building construction must be closed with a resistance screen (safety net) between two protection platforms.

As of 2006, technology denominated "Redes de Seguridad Sistema V" or "Redes de Seguridad con soporte tipo horca" [30], based on EN-1263-1 [31], was adopted, providing the use of new systems of collective protective in Brazil, as an alternative to the use of secondary protection platforms. The new CPS is called Height-Falls-Limiting System (HFLS) (in Portuguese: SLQA-“Sistemas Limitadores para Quedas de Alturas") [16], and Fig. 3 shows an example of this also called "safety net type V" (SNTV). The system follows the rise of the tower structure, involving the entire perimeter of the three highest floors. It is available in light, intermediate, and heavy versions. The SNTV set comprises a safety net, support rope, and the support system, formed by a metal component type gallow, hooks for fixing the

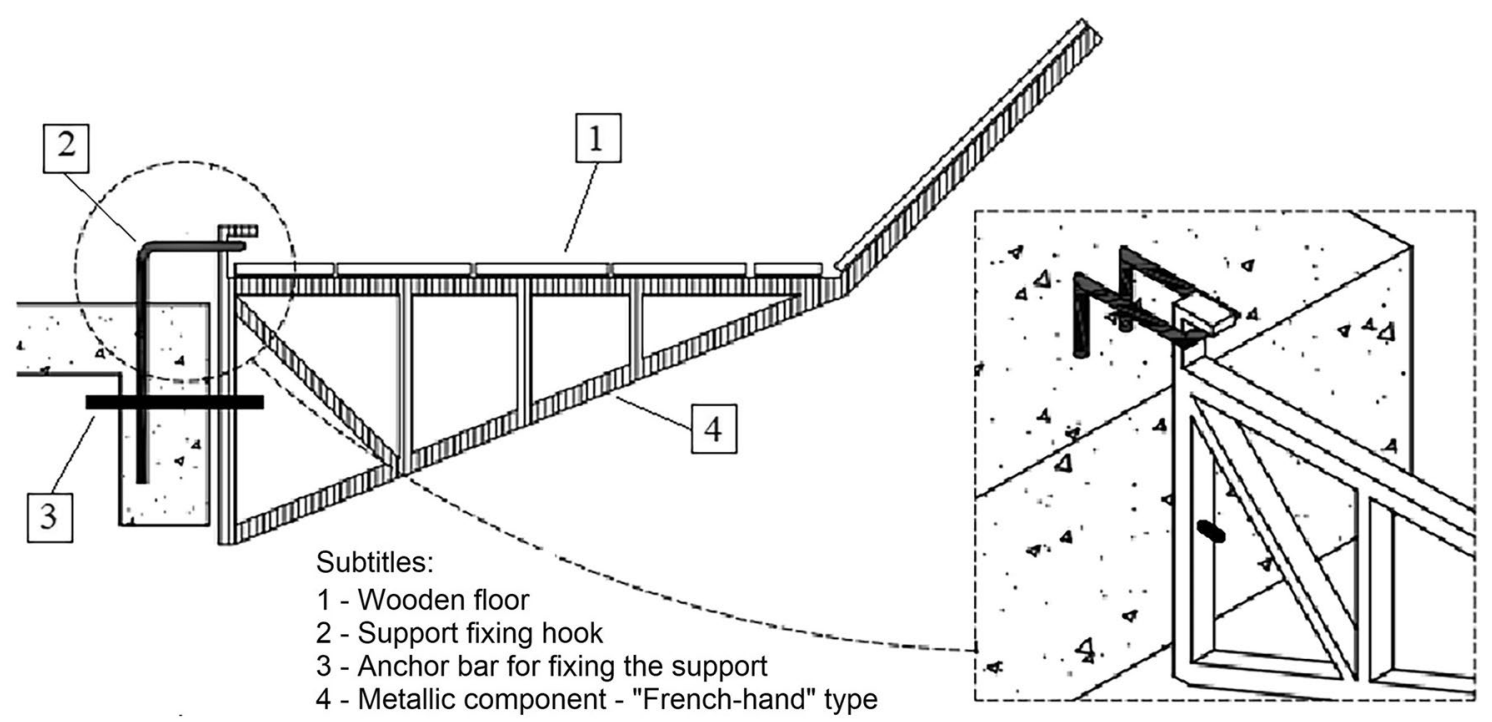

Fig. 2 Protection platform elements. Source: [32] 


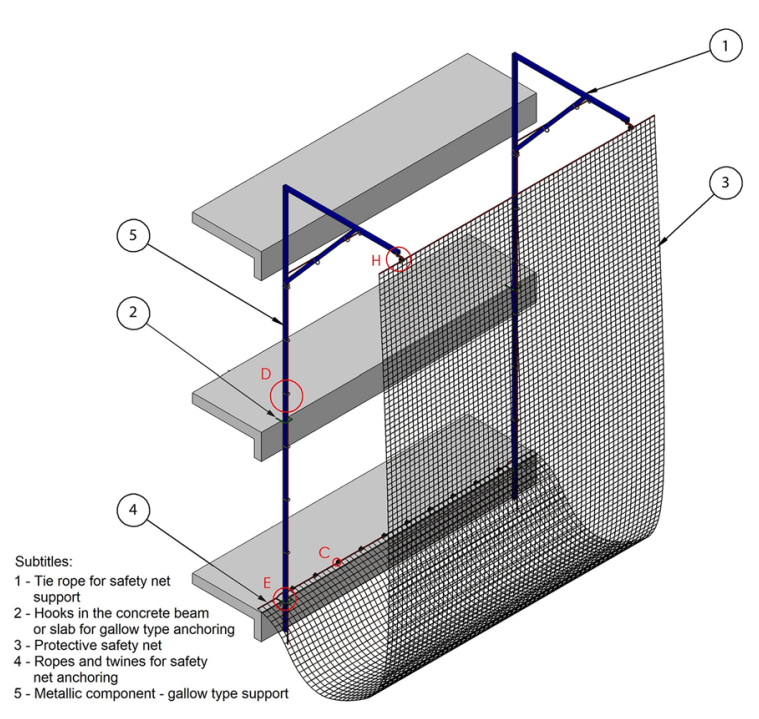

Fig. 3 Protection system with safety nets (SNTV). Source: [33]

gallow element, and hooks for anchoring the net at the bottom.

The two systems presented have similar functions: the limitation of materials and reducing people's fall. However, workers must wear seat belts attached to lifeline systems to prevent falling from a height. Every CPS must be previously dimensioned to guarantee the necessary efficiency as a barrier. The requirements for CPS design are defined in item 18.13-protection measures against falls from a height in the NR-18 [16]. The recommendations indicate the elaboration of the CPS safety project and the management practices of the system in operation. The project must be calculated by a legally qualified professional, registered in the calculation memory [32]. In the case of platforms, [32] determines that for the calculation of the components, all active loads must be provided: structural element's weight, dynamic-wind action, connection efforts with the facade screens, accumulation of debris, the overhead for maintenance (cleaning services), and the weight of suspended scaffolding (rocker) during the coating service and of the operators responsible for assembly. In SNTV, the system must be fixed with a height of 3-6 m, depending on the model, and must prevent falling objects and people, considering the impact load of a worker with $80 \mathrm{~kg}$.

To avoid incompatibilities, the designer must present the collective protective details with the technical specifications of the materials incorporated into the CPS, clearly presented in the design to facilitate its constructability. The specification of the CPS and the technical characteristics of the materials and components shall be descriptive, precise, complete, and orderly. The design should be easy to understand and provide executing details.

The CPS, in general, are currently available in the Brazilian market in the industrial form (prefabricated), usually produced with metallic components and wood for closing. The handcrafted CPS (made on-site) are generally made of wood. The CPS design and sizing criteria are still incipient and/or little divulged by the academy or manufacturers. The manufacturers of industrially produced CPS assume the technical responsibilities for their use to be commercially marketed. These manufacturers must have in their staff skilled professionals to develop specification descriptions with details of the installation, service, and disassembling of these CPS and the characteristics regarding strength, durability, and maintenance.

The innovations in the market and their potential use in construction must also be known. We can say that several technological solutions need to be further studied and disseminated to improve workers' safety in the construction site. Thus, it is essential to know the availability of products on the market and the technical and legal guidelines for their correct use during the production process in construction. The following will present two technical solutions of CPS for buildings in Brazil.

\section{Case study}

The case study is an empirical investigation of a contemporary phenomenon within a real-life context. The methodological process of this case study consists of the following techniques: bibliographical research, preparation of the research script, visits to two construction sites,

\begin{tabular}{|c|c|c|}
\hline Item & Construction site $\mathrm{A}$ & Construction site $B$ \\
\hline Date visit & July 20, 2015 & April 22, 2016 \\
\hline $\begin{array}{l}\text { Duration of the construc- } \\
\text { tion phase }\end{array}$ & January 2014-April 2017 & January 2014-February 2018 \\
\hline Number of floors & 10 & 28 \\
\hline Floor size & $600 \mathrm{~m} 2$ & $560 \mathrm{~m} 2$ \\
\hline Size building land & $1.162 \mathrm{~m} 2$ & $1.800 \mathrm{~m} 2$ \\
\hline Collected documents & Secondary platform design & SNTV design and calculation memory \\
\hline
\end{tabular}




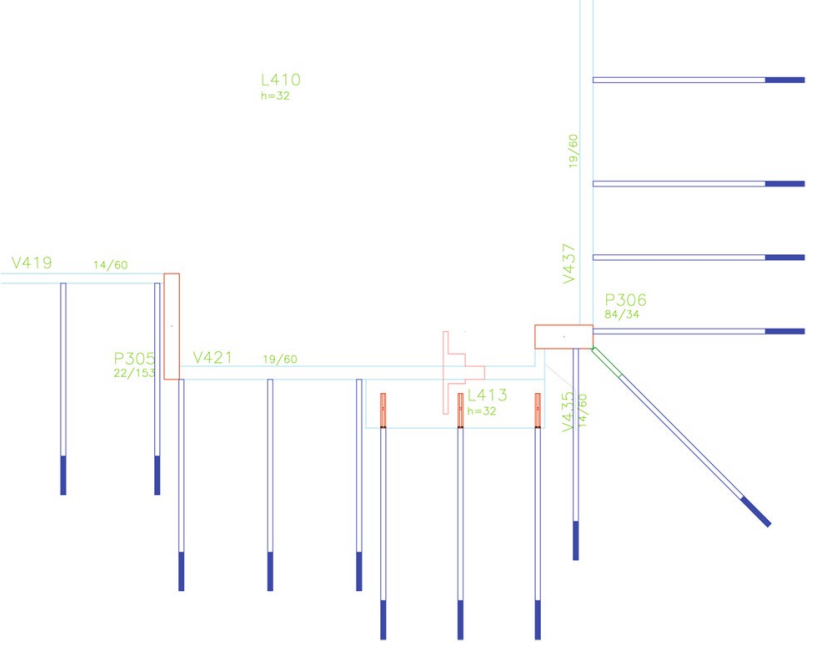

Fig. 4 Detail of the safety secondary platforms design in construction site A. Source: construction site A

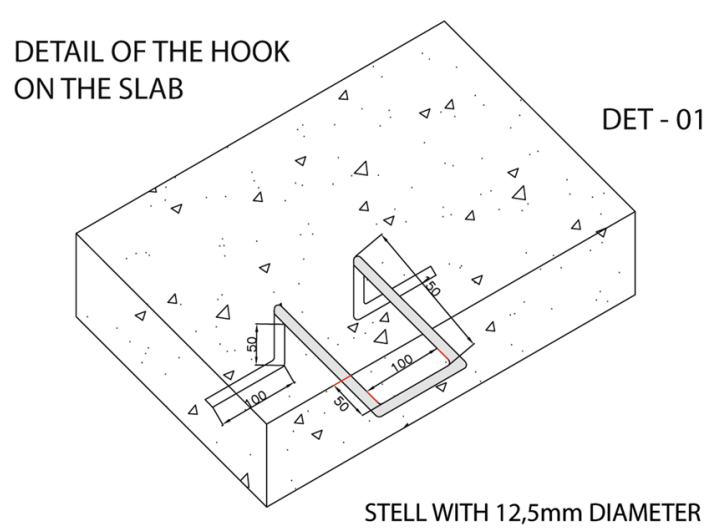

Fig. 5 Details of the fixation of the hook of the platform on the slab's border. Source: construction site A

a collection of documents, such as the CPS design, and recording situations observed through photos. The two construction sites visited were in the cities of São Carlos and Ribeirão Preto, both in the State of São Paulo, Brazil. The buildings were in an urban area, classified as a "residential area" with houses around. The authors visited the indicated date and were received by the engineers of the respective works, according to Table 1 .

Thus, a diagnosis of the use of these two CPS in Brazil will be made, and critical points of comparison between them will be identified. The assessment will be qualitative, like that carried out by [13].

\subsection{Construction site $A$}

Construction site $A$ is a building of a conventional structure in reinforced concrete and ceramic block sealing. The primary platform was installed at the level of the first slab, according to the NR-18 [16]. The CPS observed in the construction site A was the secondary platform executed on every three slabs on the floors accompanying the execution of the sealing. It was possible to access the design of secondary platforms that contained the location of metallic supports. It was verified during the visit, there was only one secondary platform at the level of the sixth slab. There should be another platform at the ninth slab level as there was service running on the roof. According to NR-18, the platform should only be removed when the periphery seal is completed to the platform immediately above.

The CPS design has been developed internally by the company safety technician, according to the builder's technical and managerial guidelines, with the main objective of the quantitative determination of materials. For the safety technician, the tray and peripheral protection systems were not difficult to assemble and should follow the assembly guidelines of parts determined by design with safety. We were also informed that the company reused the metal profile trays in other sites.

The design of the secondary platform was assigned for analysis and comparison with the real situation at the construction site, as shown in Fig. 4. The components of the platform observed were metallic component "French-hand," fastening hooks concreted next to the structural slab (Fig. 5), screws, wood for the floor, extenders, and particular parts for fixing the metallic components.

The analysis of the design indicated the position of the metal brackets-metallic component "French-hand"on the floor plan, as shown in Fig. 2. However, dimensions of the metal components, location of hooks, and attachment points of the safety cables were not found in the design. The connection of the metal profiles to the concrete structure was employing anchoring hooks, as shown in Fig. 6 in border extremital. It was observed that the tray floor was composed of wooden battens and plywood nailed to the boards to improve their setting.

The fixation of the metallic component to the concrete structure could happen in three different ways, making it necessary for the designer to illustrate the situations in the design of the CPS: directly at the edge beam, in a place with a cantilevered slab (Fig. 6) and at the ends of the floors (Fig. 7). In Fig. 6, a support element (red) was provided in the lower slab, and in Fig. 7, an extension (green) was foreseen to guarantee the lateral intersection of the platform. However, in the direct 


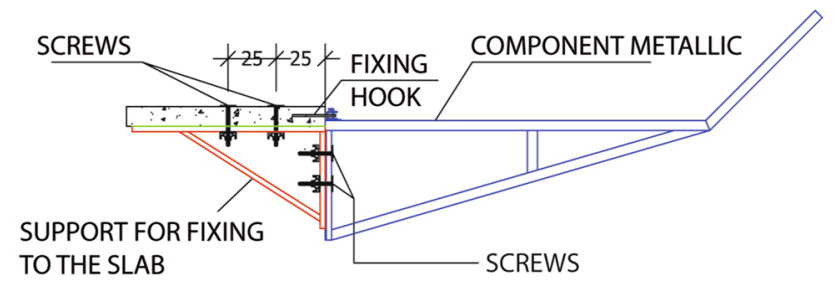

Fig. 6 Metallic component fixing in a cantilevered slab. Source: construction site $\mathrm{A}$

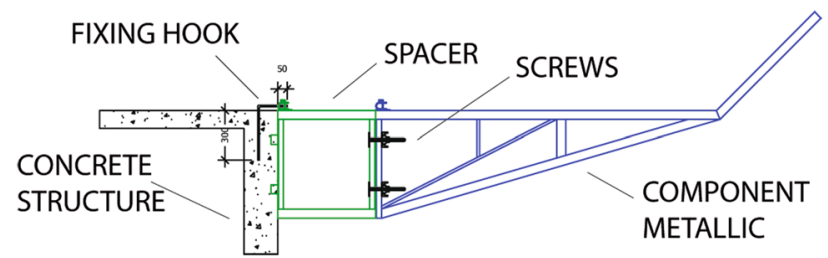

Fig. 7 Metallic component fixing in at the ends of the floors. Source: construction site $A$

fixation to the beam, the presence of the anchor bar or screws was not observed.

The workers assigned for the assembly, disassembly, and maintenance of the CPS in construction site A made use of a lifeline to execute these tasks. It was observed that the work had a safety technician available throughout the working period. The safety engineer kept up with the work periodically.

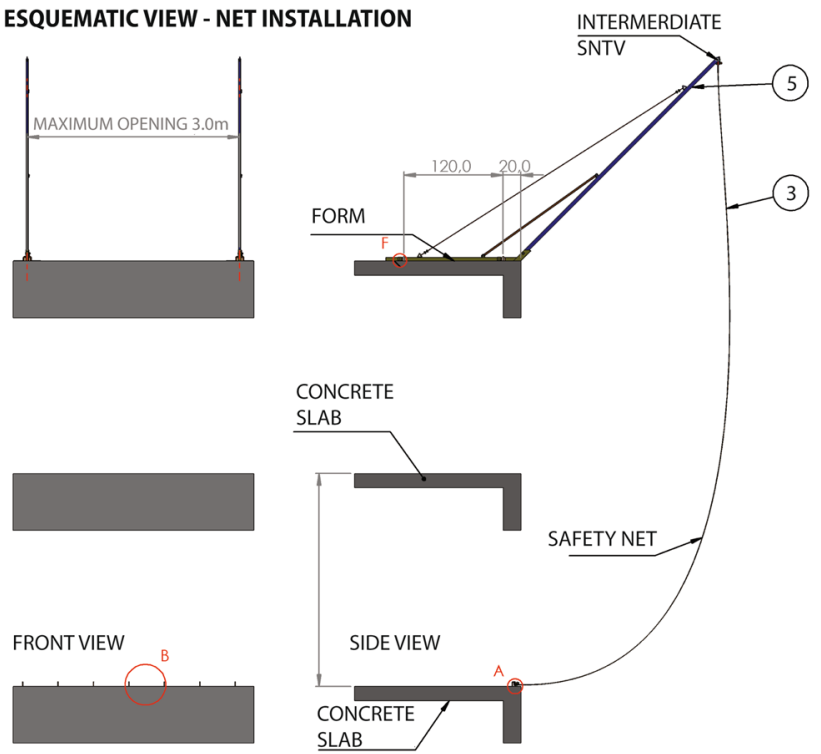

Fig. 9 Detail of the intermediate SNTV installation design. Source: construction site $B$

\subsection{Construction site B}

The development of construction site B was a conventional structure building with ceramic blocks sealing. The primary platform was installed at the level of the first slab, according to the NR-18 [16]. During the visit to construction site $B$, we were informed by the head of the company
Fig. 8 Detail of the heavy SNTV installation design. Source: construction site B
SCHEMATIC VIEW - NET INSTALLATION WITH CONCRETED HOOK

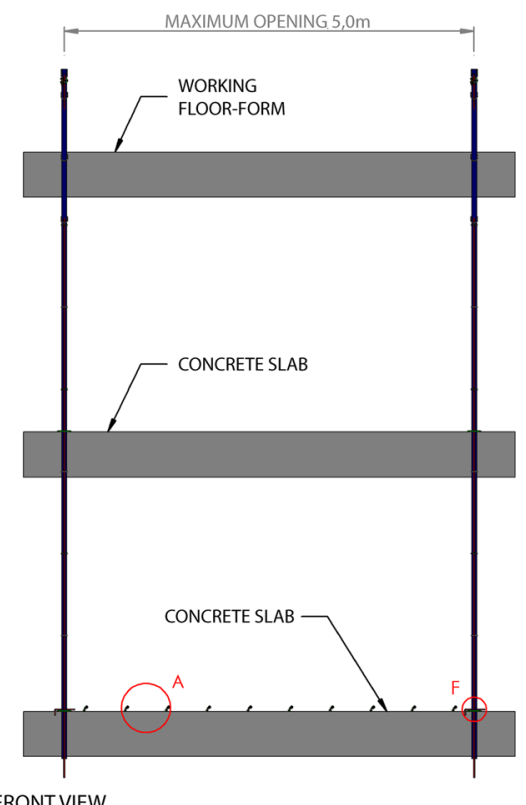

FRONT VIEW

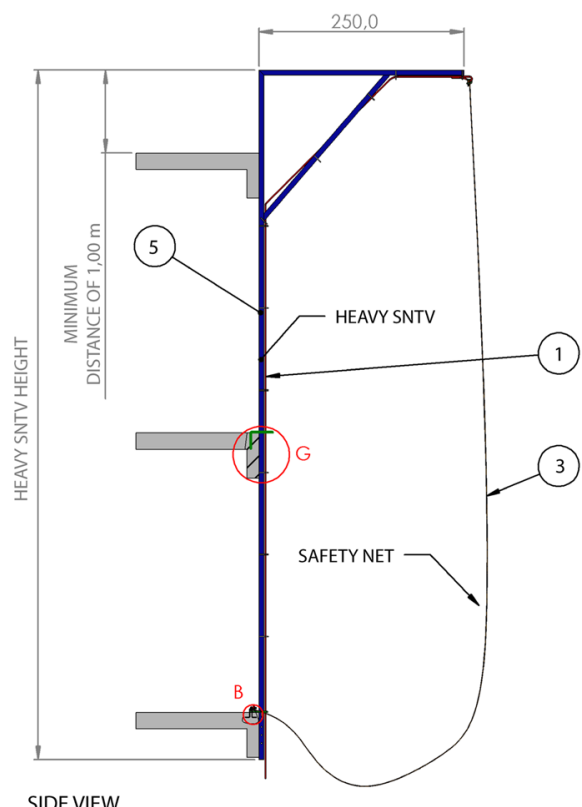

SN Applied Sciences 


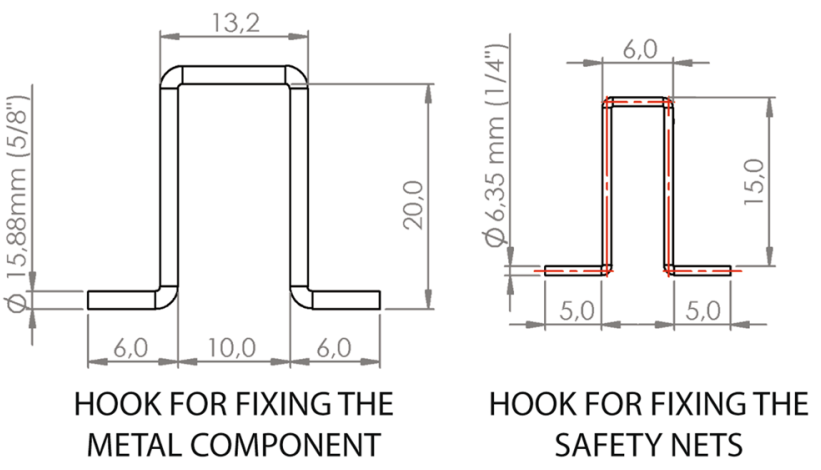

Fig. 10 Hooks for fixing the metallic component of the intermediate SNTV and safety nets. Source: construction site B

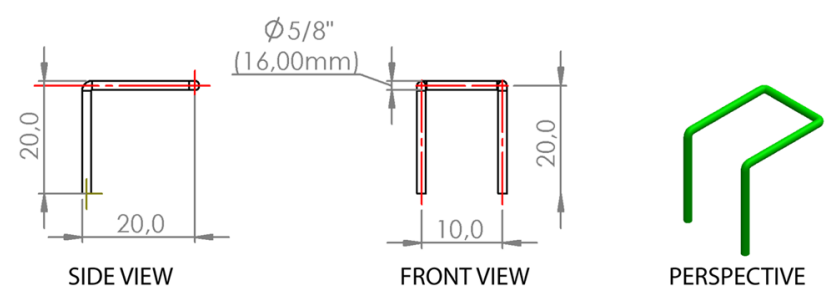

HOOK FOR FIXING OF THE METAL COMPONENT

Fig. 11 Hook for fixing the metallic component of the heavy SNTV. Source: construction site B

that they reused the metal profiles of the primary platform from other works of the company.

The CPS chosen for this work were the SNTV in two different categories: the heavy-serving the execution of the concrete structure, and the intermediate-accompanying the execution of the external masonry. It was observed that the heavy SNTV system was always installed above the intermediate SNTV system, being both lifted simultaneously to the upper floors. SNTV intermediate and heavy systems designs were prepared by an external safety designer responsible for the resistance calculation, including the support for possible falls resistance. Figures 8 and 9 present schematic views of the assigned design for analysis of the two SNTV. The heavy (Fig. 8) and intermediate (Fig. 9) SNTV were executed on the floors every three slabs before sealing.

The fixation of the components to the concrete structure is relevant information. The designer must illustrate the situations in the design of CPS: hooks for fixing the intermediate SNTV and safety nets (Fig. 10) and hooks for fixing the heavy SNTV (Fig. 11).

For fixing of metallic supports of the platform main, the hooks were positioned in the edge beams. The hooks were positioned in the concrete slabs to fix the intermediate SNTV, and the hooks were placed in the pillars to fix the heavy SNTV, increasing the rigidity of the system. All hooks must be installed when concreting the respective elements of the building structure.

The assigned workers to do the assembly, disassembly, and maintenance of the CPS and other services on the slab made use of the lifeline to execute them. For this work, the company had an exclusive safety technician and a sporadic safety engineer monitoring the activities.

Table 2 Observation items of the CPS

\begin{tabular}{|c|c|c|}
\hline Observation items & Construction site $\mathrm{A}$ & Construction site $B$ \\
\hline Visit companion & Resident civil engineer & Resident civil engineer \\
\hline The visiting companion was aware of another type of CPS & No & Yes \\
\hline The full presence of the safety technician & Yes & Yes \\
\hline Periodic presence of the safety engineer & Yes & Yes \\
\hline Existence of the specific design for CPS & Yes, prepared by the safety technician internal & $\begin{array}{l}\text { Yes, prepared by the safety } \\
\text { technician external }\end{array}$ \\
\hline Existence of professional technical responsibility & Yes & Yes \\
\hline Full perimeter closure & No, not provided for guardrail & Yes \\
\hline CPS observed & $\begin{array}{l}\text { Secondary platform-presented only one plat- } \\
\text { form, when the correct one should be two }\end{array}$ & SNTV intermediate and heavy \\
\hline Detail of hooks for connection to the concrete structure & Yes & Yes \\
\hline $\begin{array}{l}\text { Measurements and spacing of metal components in the } \\
\text { design of the floor of the structure }\end{array}$ & No & No, only in the details \\
\hline Lifeline design & No & No \\
\hline Lifeline use & Yes & Yes \\
\hline Primary platform & Present & Present \\
\hline What conditions is the primary platform on? & Good & Good \\
\hline Frequency of cleaning platforms & Not known & Weekly \\
\hline
\end{tabular}




\subsection{General analysis}

As can be seen, the two construction sites have designs for safety for the CPS, indicating the concern with the dimensioning and installation of this equipment. The general analysis of the CPS studied can be seen in Table 2 .

There were no accidents and incidents during our visiting period. However, some factors were observed, which can increase the workers' risk of accidents such as the existence of openings in the CPS, overload caused by the concentration of residues on the wooden floors of platforms, and lack or precariousness of materials containment screens. In the construction sites visited, it was possible to study the CPS designs. It is essential to mention that, because this is a project foreseen by the PCMAT in Brazil, its non-compliance makes the company susceptible to fines and penalties.

Regarding the connection of the part or metal profile that fixes the protection system with the building, the solutions found were the use of hooks for the anchorage. During the literature review [32], it was found that the option of fixing the metallic component "French-hand"

Table 3 Attendance the requirements of the item 18.13 of NR-18 standard

\begin{tabular}{|c|c|c|c|}
\hline Levels & Item 18.13 of NR-18 & Construction site $\mathrm{A}$ & Construction site $B$ \\
\hline \multirow[t]{6}{*}{ Presentation } & 1. CPS design was prepared by a legally qualified professional & $Y$ & $Y$ \\
\hline & $\begin{array}{l}\text { 2. CPS design contains technical descriptive details of the assembly phases, dis- } \\
\text { placement of the systems during the evolution of the work, and disassembly }\end{array}$ & $\mathrm{N}$ & $\mathrm{N}$ \\
\hline & $\begin{array}{l}\text { 3. CPS design is integrated with the work conditions and environment program in } \\
\text { the construction industry-PCMAT }\end{array}$ & $\mathrm{N}$ & $\mathrm{N}$ \\
\hline & 4. CPS design presents details of the metallic components & Y & Y \\
\hline & 5. CPS design presents details about the hooks for fixing the metallic components & Y & Y \\
\hline & 6. CPS design presents details about the hooks for fixing the safety nets & $\mathrm{N}$ & Y \\
\hline \multirow[t]{11}{*}{ Components } & 7. Metallic component meets the specifications and dimensions of the standards & $\mathrm{N}$ & $\mathrm{N}$ \\
\hline & $\begin{array}{l}\text { 8. The maximum distance between the supporting elements is defined in the } \\
\text { design }\end{array}$ & $\mathrm{N}$ & Y \\
\hline & 9. Safety net meets the color specifications and standard distance between nodes & NA & Y \\
\hline & 10. The safety net has a uniform mesh throughout its length & NA & Y \\
\hline & 11. Safety net meets the manufacturing standard & NA & Y \\
\hline & 12. Safety net (or slab screen) is fixed between two elements & $\mathrm{N}$ & Y \\
\hline & $\begin{array}{l}\text { 13. The fixing of the safety nets anchoring points meets the recommended dis- } \\
\text { tances }\end{array}$ & NA & Y \\
\hline & 14. Safety net cross is carried out by specialized professionals & NA & $\mathrm{N}$ \\
\hline & $\begin{array}{l}\text { 15. Fabrics (screens) are placed on the safety net to prevent small materials from } \\
\text { falling }\end{array}$ & NA & $\mathrm{N}$ \\
\hline & 16. Support and perimeter ropes meet manufacturing standards & NA & Y \\
\hline & 17. Mechanisms are provided for fixing the floorboards in the platform & Y & NA \\
\hline \multirow[t]{7}{*}{ Management } & $\begin{array}{l}\text { 18. CPS receives a weekly inspection to cleaning residues on its surfaces or net- } \\
\text { works }\end{array}$ & $\mathrm{N}$ & Y \\
\hline & $\begin{array}{l}\text { 19. CPS has a weekly inspection to check the condition of all its elements and } \\
\text { attachment points }\end{array}$ & $\mathrm{N}$ & Y \\
\hline & 20. After the weekly inspection, the necessary corrections are made & $\mathrm{N}$ & $\mathrm{Y}$ \\
\hline & $\begin{array}{l}\text { 21. The assembly, displacement, and disassembly services are supervised by the } \\
\text { technician responsible for the execution of the work }\end{array}$ & Y & Y \\
\hline & $\begin{array}{l}\text { 22. CPS components are stored in an appropriate, dry place and protected from } \\
\text { deterioration }\end{array}$ & Y & Y \\
\hline & 23. CPS components are exclusively used for installation according to this design & Y & Y \\
\hline & $\begin{array}{l}\text { 24. CPS is used until the completion of the periphery sealing and structure activi- } \\
\text { ties }\end{array}$ & Y & Y \\
\hline \multirow[t]{5}{*}{ Levels } & Item 18.13 of NR-18 & Construction site $\mathrm{A}$ & Construction site B \\
\hline & Quantity of "Yes" (Y) & 8 & 18 \\
\hline & Quantity of "No" (N) & 9 & 5 \\
\hline & Quantity of "Not Applicable" (N/A) & 7 & 1 \\
\hline & Note & 4,7 & 7,8 \\
\hline
\end{tabular}


of platform CPS through anchoring bars would be more efficient in locking the rotation of the part, as it may occur dislocation in the event of strong winds. Nevertheless, such a solution was not found in practice.

The lack of cleaning of the platform floor can be a problem since the accumulation of waste can cause an overload greater than that predicted in the dimensioning. Cleaning is usually performed by workers who move over platforms, which also increases overload in this equipment. To accomplish such a task, the employee had to project out of the building perimeter, thus exposing him/ her to additional risk. However, such a situation of exposure to risk does not occur with the system of protection with safety nets. The removal of residues accumulated in the CPS net can be carried out with the aid of a cable or similar tool that takes the protective network to the edge of the building where the worker is attached to the lifeline.

A positive point of the site's constructions visited was that they used the lifeline to assemble and disassemble the CPS, which is of the utmost importance, in addition to being legally recommended. In the event of a fall, the worker will be saved by the safety cable connected to the lifeline system. Namely, the CPS is present as a precaution and to sustain the waste from other building services.

Table 3 presents the attendance of the two CPS to the respective executive design and the guidelines of NR-18, considering the division in the levels of presentation of the project, definition of components, and safety management. In case an item is not related to the practice or the respective CPS, the evaluation "not applicable" (NA) will be indicated. The calculation of the note was performed, as proposed by [34], identifying the amount of affirmative, negative, and non-applicable results.

NOTE $=\frac{\sum Y E S}{\sum Y E S+\sum N O} \cdot 10$

Compliance with item 18.13 of NR-18 can be calculated by multiplying the note obtained by 100 . The CPS of construction site $B$ better met the requirements of the NR-18 standard, with $78 \%$ against $47 \%$ of the CPS of construction site A. However, both designs had significant deficiencies, such as not providing for the disassembly and reassembly of the equipment. Although NR-18 mentions the importance of inserting the CPS design into the PCMAT, it was not made available for verification. The CPS design for construction site A presented the distribution of the metallic components on the periphery of the floor but did not place the corresponding dimensions and distances. The location will be necessary for fixing the support hooks during the concreting of the slabs. The CPS design for construction site B presented the distance measures between the components and the anchoring hooks only in the details, not showing the distribution and quantification of parts on the floor.

Another analysis concerns the details of the components and respective information for manufacturing. The details of the fixing hooks were considered sufficient, as it was only a question of cutting and folding rebar identified in terms of gauge and resistance. However, there was no information available for manufacturing concerning metallic components, such as identifying measures of metallic elements, types of the weld, and necessary painting. Regarding the safety net for use in SNTV, the design presented the same recommendations as to the standard NR-18, not identifying details that could help in understanding the requirements. The management item did not show good results at construction site $A$, despite having a full-time safety technician.

The requirements in Table 3 facilitated the visualization of the compliance of CPS concerning the items of NR-18. It is possible to observe that SNTV has safety advantages over the secondary platform. During the visit to the works, it was observed that the protection system with platforms where, during the execution of the assembly, disassembly, and cleaning of the wooden platform floor, the worker positions himself outside the perimeter of the building, thus creating additional risk. Such a situation is not observed when using a safety net protection system. Another factor that explains the superiority of SNTV is that only the safety nets protection system completely avoids, in the event of a fall, the projection of the worker outside the protection perimeter of the CPS. For reasons like this, the adoption of the secondary platform is gradually being replaced by SNTV in several construction sites in Brazil. However, the technical design must evolve to represent the probable real situations.

\section{Conclusion}

The management of occupational safety and health (OSH) in the construction sector involves several aspects such as the elaboration of technical design of collective protection systems and compliance with regulatory standards and legislation. The execution of CPS design should be considered as an essential requirement, adding value to the construction process through the anticipated planning of the improvement in the working conditions. In general, the common problem in the design process is the lack of knowledge in the procedures of assembling, moving, or disassembling the CPS, whose design does not detail ways 
to improve or ensure the safety of workers and maintenance of equipment.

Despite the study restricted to two construction sites and two CPS, one can observe the importance of this analysis. It contributes reduction or avoidance to accidents that can cause loss of life, reduce delays in the schedule, and increase direct and indirect costs. The study also demonstrated that the existence of a CPS does not guarantee that it is correctly designed and executed. A checklist of design conditions can be provided as a form of control. Standards and best practices must be fully met to achieve the desired result.

It is also believed that some problems of implantation and use of CPS in Brazil may decrease with the offer of technical-scientific publications that expand the dissemination of this knowledge. This paper accomplished a fundamental goal of comparing two CPS based on the legal requirements in Brazil and pointing out opportunities for improvement in the process and the design of collective protection. Despite the advantages of SNTV, it is still little known in Brazil, mainly because it is characterized as a novelty in the construction industry. There is potential for new suppliers of the components to offer the product in the Brazilian market.

It is expected that the training of health and safety professionals will consider the need for instruction on the development of the design process addressing concepts and aspects of safe work. The young, newly trained architects and engineers in the EU are more familiar with and tend to assimilate better the planning concepts of workplace safety than professionals with more extended training [35]. It is also hoped that the schools in Brazil educate professionals with a greater interest in improving the $\mathrm{OSH}$ area to become an increasingly present reality in construction sites.

It is concluded, therefore, that if a CPS is activated for the primary function for which it was designed-to prevent people from falling, it must fully assist the worker who needs protection. On the other hand, a CPS can perform its function without the need for triggering, as it is designed to protect workers in general and demonstrates to a culture of safety. To ensure this improvement, it is also essential to raise awareness among construction agents, workers, and labor auditors. We suggest training programs of civil construction workers and for a better understanding of the working conditions for the inspection agencies. With the demand exerted by entrepreneurs and inspection agents, it is possible to move forward on new solutions aimed at safety during the implementation and maintenance phases, focusing on developing a specific design of a protective system.

The results of this study will help managers and safety designers to carry out analyses between different CPS solutions by presenting a comparison method based on the country's legislation and the design with safety. As a continuation of the research, modeling techniques can be applied that allow the representation of the complexity and the understanding of protection systems for civil construction. With this, a decision-making method can be built to prevent falls from a height and understand the nature of strategic risk mitigation, thus decreasing the likelihood of fatal injuries on construction sites.

Funding Coordination of Superior Level Staff Improvement (CAPES), Finance Code 001. Research project Technologies for Sustainable Social Interest Housing Construction Sites (CANTECHIS), supported by the Financier of Studies and Projects (FINEP), number 01.11.0056.00.

Code availability Code availability is not applicable.

Data availability Data availability not applicable.

\section{Compliance with ethical standards}

Conflicts of interest The authors declare that they have no conflict of interest.

\section{References}

1. Union E (2011) Non-binding guide to good practice for understanding and implementing directive $92 / 57 /$ EEC on the implementation of minimum safety and health requirements at temporary or mobile construction sites. Luxemb. https://doi. org/10.2767/31797

2. Omale RP, Oriye $O$ (2013) Health risks and safety of construction site workers in Akure Nigeria. Scott J Arts Soc Sci and Sci Stud 13(1):75-94

3. Bureau of Labor Statistics, USA Department of Labor (2015) Fatal falls in the private construction industry, 2003-2013. https://www.bls.gov/opub/ted/2015/fatal-falls-in-the-priva te-construction-industry-2003-2013.htm

4. Bobick TG, McKenzie EA Jr, Kau TY (2010) Evaluation of guardrail systems for preventing falls through roof and floor holes. J Saf Res 41(3):203-211. https://doi.org/10.1016/j. jsr.2010.02.008

5. Brasil, Ministério Público do Trabalho (2019) Digital Observatory of Safety and Health of Work. https://observatoriosst.mpt. mp.br/

6. Ajith S, Sivapragasam C, Arumugaprabu V (2019) Quantification of risk and assessment of key safety factors for safe workplace in Indian building construction sites. Asian J Civ Eng 20:693-702. https://doi.org/10.1007/s42107-019-00136-y

7. Nadhim EA, Hon C, Xia B, Stewart I, Dongping F (2016) Falls from height in the construction industry: a critical review of the scientific literature. Int J Environ Res Public Health. https://doi. org/10.3390/ijerph13070638

8. Liy CH, Ibrahim SH, Affandi R, Rosli NA, Nawi MNM (2016) Causes of fall hazards in construction site management. Int Rev Manag Mark 6(8):257-263 
9. British Association Health and Safety Executive (HSE) (2005) Number 735: Health and Safety: The Work at Height Regulations 2005. Statutory Instruments. London. https://www.legis lation.gov.uk/uksi/2005/735/contents/made

10. Uchoa J, Sousa MJA, Silva L, Cavaignac A (2019) FMEA method application based on occupational risks in the construction industry on work at height: a theoretical contribution. Int J Adv Eng Res Sci 6(10):261-278

11. García MDLN (2010) Consideraciones respecto a los sistemas provisionales de protección de borde. Tesis Doctoral. Madrid: Universidad Politécnica de Madrid. https://oa.upm.es/5893/

12. Hamm J, Money AG, Atwal A, Paraskevopoulos I (2016) Fall prevention intervention technologies: a conceptual framework and survey of the state of the art. J Biomed Inform 59:319-345. https ://doi.org/10.1016/j.jbi.2015.12.013

13. Adam JM, Pallarés FJ, Calderón PA (2009) Falls from height the floor slab formwork of buildings: current situation in Spain. J Saf Res 40:293-299. https://doi.org/10.1016/j.jsr.2009.07.003

14. European Parliament and the Council of the European Union (2009) Directive 2009/104/EC: Use of Work Equipment. https:// osha.europa.eu/en/legislation/directives/3

15. Occupational Safety and Health Administration (OHSA) (2019) Standard Number 1926.502 - Fall protection systems criteria and practices. https://www.osha.gov/laws-regs/regulations/stand ardnumber/1926/1926.502

16. Brasil, Ministério do Trabalho e Emprego (2018) NR-18: Condições e Meio Ambiente de Trabalho na Indústria da Construção. https://enit.trabalho.gov.br/portal/images/Arquivos_SST/SST_ NR/NR-18.pdf

17. Saurin TA, Formoso CT (2008) Guidelines for considering construction safety requirements in the design process. In: Hinze J, Bohner J, Lew J (eds) (2008) Evolution of and directions in construction safety and health, CIB: Gainesville. Florida, USA, pp 115-129

18. Martins MS, Serra SMB (2003) Prevention systems against falls from height in the building subsector. In: 1 st International Symposium The Design, The Safety, The Structure. Conferencepaper. https://www.academia.edu/10317192/Prevention_syste ms_against_falls_from_height_in_the_building_subsector

19. Cameron I, Gillan G, Duff AR (2007) Issues in the selection of fall prevention and arrest equipment. Eng Constr Archit Manag 14(4):363-374. https://doi.org/10.1108/09699980710760676

20. Croner-i (2017) Designing for safety: in-depth. https://app.crone ri.co.uk/topics/designing-safety/indepth

21. Thorpe $B(2005)$ Health and safety in construction design. Gower Publishing, England

22. Toole TM, Gambatese JA (2008) The trajectories of prevention through design in construction. J Saf Res 39(2):225-230. https ://doi.org/10.1016/j.jsr.2008.02.026
23. American Society of Safety Professionals (ASSP) (1994) Position statement on designing for safety. https://www.assp.org/posit ion-statements

24. Hinze J, Wiegand F (1992) Role of designers in construction worker safety. J Constr Eng Manag 118:677-684. https://doi. org/10.1061/(ASCE)0733-9364(1992)118:4(677)

25. Manuele FA (1997) On the practice of safety. John Wiley \& Sons, New York

26. Tymvios N, Gambatese JA (2016) Perceptions about design for construction worker safety: viewpoints from contractors, designers, and university facility owners. J Constr Eng Manag 142(2):1-11. https://doi.org/10.1061/(ASCE)CO.19437862.0001067

27. Safe Work Australia. Safe design. https://www.safeworkaustral ia.gov.au/safe-design\#examples-of-safe-design

28. Baxendale T, Jones $\mathrm{O}$ (2000) Construction design and management safety regulations in practice-progress on implementation. Int J Project Manag 18(1):33-40. https://doi.org/10.1016/ S0263-7863(98)00066-0

29. Hollnagel E (2004) Barriers and accident prevention. Ashgate, Burlington, USA

30. Bellmunt JJ (1985) NTP 124: Redes de seguridad. 12p. https:// www.insst.es/documents/94886/326801/ntp_124.pdf/40e0d 0b8-fc1c-4fd9-b68f-859a13619f66

31. European Standard (2018) UNE EN 1263-1: Temporary works equipment - Safety nets - Part 1: Safety requirements, test methods. 45p. https://www.en-standard.eu/une-en-1263-1-2018temporary-works-equipment-safety-nets-part-1-safety-requi rements-test-methods/

32. Comitê Permanente Regional de Ribeirão Preto (CPR-Ribeirão) (2015) Sugestão técnica de procedimento proteções coletivas contra queda de altura. 36p. https://www.sindusconsp.com.br/ wp-content/uploads/2015/11/Acesse-aqui-a-\%C3\%ADntegrado-manual.pdf

33. Brazil, Ministério do Trabalho e Emprego (2004) Sistema de segurança contra quedas. São Paulo: CD-Rom.

34. Saurin TA, Formoso CT, Guimarães LBM (2004) Safety and production: a integrated planning and control model. Constr Manag Econ 22(2):159-169. https://doi.org/10.1080/01446 19042000201367

35. Martinez Aires MD, Rubio Gamez MC, Gibb AGF (2016) The impact of occupational health and safety regulations on prevention through design in construction projects: perspectives from Spain and the United Kingdom. Work: A J Prev Assess Rehabilit 53(1):181-191

Publisher's Note Springer Nature remains neutral with regard to jurisdictional claims in published maps and institutional affiliations. 